\title{
Maternal overweight and obesity in early pregnancy and risk of infant mortality: a population based cohort study in Sweden
}

\author{
OPEN ACCESS
}

\begin{abstract}
Stefan Johansson consultant neonatologist ${ }^{1}$, Eduardo Villamor associate professor of epidemiology ${ }^{2}$, Maria Altman postdoctoral researcher ${ }^{1}$, Anna-Karin Edstedt Bonamy paediatrician ${ }^{1}$, Fredrik Granath associate professor of medical statistics ${ }^{1}$, Sven Cnattingius professor of reproductive epidemiology ${ }^{1}$

${ }^{1}$ Clinical Epidemiology Unit, Department of Medicine, Solna, Karolinska University Hospital, Karolinska Institutet, SE-171 76 Stockholm, Sweden; ${ }^{2}$ Department of Epidemiology, University of Michigan School of Public Health, Ann Arbor, Michigan, United States
\end{abstract}

\begin{abstract}
Objective To investigate associations between maternal overweight and obesity and infant mortality outcomes, including cause-specific mortality.

Design Population based cohort study.

Setting and participants 1857822 live single births in Sweden 1992-2010.

Main outcome measures Associations between maternal body mass index (BMI) in early pregnancy and risks of infant, neonatal, and postneonatal mortality, overall and stratified by gestational length and by causes of infant death. Odds ratios were adjusted for maternal age, parity, smoking, education, height, country of birth, and year of delivery.

Results Infant mortality rates increased from 2.4/1000 among normal weight women (BMl 18.5-24.9) to 5.8/1000 among women with obesity grade 3 (BMI $\geq 40.0)$. Compared with normal weight, overweight (BMI 25.0-29.9) and obesity grade 1 (BMI 30.0-34.9) were associated with modestly increased risks of infant mortality (adjusted odds ratios 1.25 (95\% confidence interval 1.16 to 1.35 ) and 1.37 (1.22 to 1.53 ), respectively), and obesity grade 2 (BMI 35.0-39.9) and grade 3 were associated with more than doubled risks (adjusted odds ratios 2.11 (1.79 to 2.49 ) and 2.44 (1.88 to 3.17$)$ ). In analyses stratified by preterm and term births, maternal BMI was related to risks of infant mortality primarily in term births ( $\geq 37$ weeks), where risks of deaths due to birth asphyxia and other neonatal morbidities increased with maternal overweight and obesity. Obesity grade 2-3 was also associated with increased infant mortality due to congenital anomalies and sudden infant death syndrome.

Conclusions Maternal overweight and obesity are associated with increased risks of infant mortality due to increased mortality risk in term births and an increased prevalence of preterm births. Maternal overweight
\end{abstract}

and obesity may be an important preventable risk factor for infant mortality in many countries.

\section{Introduction}

The high prevalence of maternal overweight and obesity may have implications for infant health, as pregnancy complications such as pre-eclampsia and diabetic disorders are more common in these women. ${ }^{1}$ Maternal weight change between consecutive pregnancies correlates linearly with risks of these obesity related pregnancy complications, suggesting a causal relationship. ${ }^{2}$

Pre-eclampsia is associated with intrauterine growth restriction and preterm delivery. ${ }^{3}$ Diabetic disorders increase the risk of congenital anomalies and may lead to macrosomia that increases the risk of birth trauma. ${ }^{4-6}$ Pregnancy complications probably explain the obesity related increased risk of medically indicated preterm delivery, but obese women are also at increased risk of spontaneous extremely preterm delivery $(\leq 27$ completed weeks). ${ }^{7}$

Research on associations between maternal body mass index (BMI) and infant mortality has not produced consistent results. Two recently published meta-analyses disagree on whether infants of overweight mothers (BMI 25.0-29.9) are at increased risk, ${ }^{89}$ and only one of these meta-analyses investigated risks during the neonatal period. ${ }^{9}$ Other studies disagree on whether there are ethnic differences. ${ }^{10}{ }^{11}$ Maternal obesity is known to increase the risk of infant deaths due to congenital anomalies, ${ }^{12}$ but research on associations with other specific causes of infant mortality is scarce. 
A nationwide cohort of more than 1.8 million liveborn, singleton infants gave us the opportunity to test the hypothesis that maternal overweight and obesity are associated with infant, neonatal, and postneonatal mortality. As maternal BMI is positively associated with risk of preterm delivery, we also wanted to investigate these associations stratified by preterm and term births. Finally, we wanted to study whether maternal overweight and obesity are associated with specific causes of infant death.

\section{Methods \\ Study design and population}

This is a population based cohort study of 1095023 women with 1857822 live single births from 22 completed gestational weeks, recorded in the Swedish Medical Birth Register from 1992 to 2010 (fig $1 \Downarrow$ ). Using the person-unique national registration number, ${ }^{13}$ the Medical Birth Register was cross linked with the national registers for cause of death, total population, and education.

Operating since 1973, the Medical Birth Register prospectively collects data on more than $98 \%$ of all births in Sweden. ${ }^{14}$ Standardised forms for antenatal, obstetric, and neonatal care are used in all antenatal and delivery units in Sweden. Recorded information is forwarded to the registry after delivery. Measured maternal weight and self reported height at the first antenatal visit have been recorded since 1992 .

The National Cause of Death Register includes information of all deaths in Sweden since 1961. ${ }^{15}$ The Swedish Register for Total Population contains information about Swedish residents since 1968 , including country of birth. ${ }^{16}$ The yearly updated Swedish Education Register records the highest level of education for Swedish residents. ${ }^{17}$

Register data on diagnoses, congenital anomalies, and causes of infant death are recorded as ICD-9 and ICD-10 codes (international classification of diseases, ninth (1992-96) and 10th (1997-2010) revisions).

The study was approved by the Research Ethics Committee at Karolinska Institutet, Stockholm, Sweden (No 2012/4:9).

\section{Exposures}

Maternal body mass index (BMI) in early pregnancy was calculated from self reported height and weight measured in light indoor clothes and without shoes at the first antenatal visit, which occurs within the first 12 weeks of gestation for $90 \%$ of pregnant women. ${ }^{14}$ Weight could not be corrected for gestational length, as the dataset lacked date for the recording. Maternal BMI was classified as underweight (BMI $\leq 18.4)$, normal (18.5-24.9), overweight (25.0-29.9), obese grade 1 (30.0-34.9), obese grade $2(35.0-39.9)$, or obese grade $3(\geq 40.0){ }^{18}$

Diagnoses were coded by a physician after delivery. Obesity related morbidities included pre-gestational hypertension (defined by self reported hypertension at first antenatal visit or by ICD-9 codes $401-405,642 \mathrm{C}$, and $642 \mathrm{H}$, and ICD-10 codes I10-I15, O10, and O11), pre-gestational diabetes (ICD-9 250 and 648A, and ICD-10 E10-E14 and O240-O243),

pre-eclamptic disorders (ICD-9 642E-642G, and ICD-10 O14 and O15), or gestational diabetes (ICD-9 648W and ICD-10

O244). In addition, to define pre-gestational hypertension, we also used self reported health information at the first antenatal visit.

In Sweden, all women are offered ultrasound pregnancy dating. The investigation is generally performed in early second trimester, and $95 \%$ of women accept this offer. ${ }^{19}$ We used the following hierarchy to estimate gestational age: early second trimester ultrasound $(81.1 \%)$, date of the last menstrual period (13.2\%), and an assessment after delivery (5.7\%). Gestational length was categorised as very preterm (22-31 weeks), moderately preterm (32-36 weeks), or term ( $\geq 37$ weeks).

Maternal age at delivery was retrieved using information from the national identification number (mother's birth date) and date of delivery. Information on self reported parity, smoking habits (previously validated using cotinine markers ${ }^{20}$ ), and maternal height was obtained at the first antenatal visit. Information on mother's educational level and country of birth was derived from the Swedish Education Register and the Swedish Register for Total Population, respectively. Variables were categorised according to table $1 \Downarrow$.

In the study population of 1857822 live single births, there were 258271 (14\%) births where maternal BMI was missing. As an additional $53916(3 \%)$ births had missing information on maternal smoking status, educational level, or country of birth, there were 1545635 births with complete information on covariates (fig $1 \Downarrow$ ).

\section{Outcomes}

Infant mortality was defined as death during the first year of life. Neonatal and postneonatal mortality were defined as infant deaths within and after the first 28 days of life, respectively.

Causes of death were categorised into 11 groups according to ICD codes (appendix A of online data supplement): congenital anomalies, birth asphyxia, other neonatal morbidities (non-asphyxia), sudden infant death syndrome (SIDS), infections, cardiovascular and pulmonary causes, endocrine and metabolic disorders, neuromuscular disorders, malignant neoplasms, external causes of deaths, and other causes.

\section{Statistics}

Mortality rates, presented as deaths per 1000 liveborn infants, were calculated as the proportion of deaths among infants at risk. Consequently, neonatal mortality rates are based on all liveborn infants, and postneonatal mortality rates are based on infants surviving the neonatal period.

Mortality risks, presented as odds ratios with $95 \%$ confidence intervals, were calculated in logistic regression models applying the generalised estimating equation method to correct for repeated pregnancies. Maternal BMI was added to the models as a continuous or categorised measurement. Adjusted models were restricted to observations with complete information on covariates, including maternal BMI, age, parity, smoking, education level, height, country of birth, and year of delivery. As obesity related complications may be in the causal pathway between maternal BMI and infant mortality, we investigated whether maternal BMI was independently associated with infant mortality in a cohort restricted to women without such complications (table B of data supplement).

Rates and risks were calculated for the whole cohort and stratified by gestational length into very preterm (22-31 weeks), moderately preterm (32-36 weeks), and term births ( $\geq 37$ weeks).

Because information on maternal BMI was missing in $14 \%$ of births, we also performed analyses after multiple imputations. BMI category was imputed using an ordinal logistic regression model predicted by gestational length, infant mortality, maternal age, parity, and year of birth. After imputation of BMI category, missing values for categories of height, smoking, education, and mother's country of birth were imputed sequentially with 
ordinal logistic regression models where the variables in the sequence already imputed were added as predictors. Ten imputed datasets were created and analysed by logistic regression applying the generalised estimating equation method. Parameters and covariance matrices were then analysed by the procedure MIANALYZE to produce estimates accounting for both random variation and the uncertainty due to repeated imputations. We restricted these analyses to overall risks of infant, neonatal, and postneonatal mortality (fig $3 \Downarrow$ ). We also assessed the sensitivity of the results after imputation by changing the order of imputed variables, adding two-factor interactions in the imputation models, and by imputing maternal BMI from previous or following pregnancies with known maternal BMI (appendix B and table $\mathrm{C}$ of data supplement). The results from the various imputation models were essentially unchanged compared with the imputation results presented in fig $3 \Downarrow$.

The number of infant deaths attributed to maternal BMI $\geq 25.0$ and smoking were estimated by calculating the population attributable fraction (PAF) using the formula shown in fig $2 \Downarrow$. The calculations excluded underweight women (BMI <18.5) as we wanted to estimate the PAF attributed to overweight and obesity in relation to normal weight. PAF among all births (table $1 \Downarrow$ ) and among term births (table $2 \Downarrow$ ) were calculated, and the numbers of infant deaths attributed to maternal BMI $\geq 25.0$ in these groups were deduced from the PAF. The PAF for smoking was estimated as opposed to non-smoking.

The SAS software package version 9.3 (SAS Institute, Cary $\mathrm{NC}$, USA) was used for statistical analyses.

\section{Results}

Among 1857822 liveborn singleton infants 1992-2010, there were 5428 infant deaths (overall infant mortality rate 2.9/1000). Two thirds of infant deaths occurred during the neonatal period (table $1 \Downarrow$ ). During the study period, the prevalence of maternal overweight and obesity in early pregnancy (BMI 25.0-29.9 and $\geq 30$, respectively) increased from $20 \%$ and $6 \%$ in 1992 to $25 \%$ and $13 \%$ in 2010 . During the same time, infant mortality rate was reduced from 4.5/1000 live births in 1992 to 2.2/1000 live births in 2010.

Infant mortality rates increased with increasing maternal BMI in early pregnancy, from 2.4/1000 among normal weight women (BMI 18.5-24.9) to 5.8/1000 among women with obesity grade 3 (BMI $\geq 40.0$ ) (table $1 \Downarrow)$. Women with missing information on BMI also had increased infant mortality rate. Infant mortality rates increased with decreasing maternal age, shorter maternal height, lower education, increasing parity, and with maternal smoking. Infant mortality rates were higher among infants to mothers born outside Sweden compared with infants of Swedish born mothers. Infant mortality rates decreased over time.

Maternal BMI was positively associated with infant mortality risks. Crude and adjusted odds ratios (95\% confidence intervals) for infant mortality per BMI unit increase were 1.04 (1.03 to 1.05 ) and 1.04 (1.03 to 1.04), respectively. Corresponding estimates for neonatal mortality were 1.05 (1.04 to 1.05) and 1.05 (1.04 to 1.06 ), and for postneonatal mortality 1.03 (1.02 to 1.04 ) and 1.02 (1.01 to 1.03), respectively. Compared with infants of normal weight mothers, infant mortality risks were modestly increased in overweight and mildly obese mothers (BMI 25.0-29.9 and 30.0-34.9, respectively), while obesity grade 2 or grade 3 (BMI 35.0-39.9 or $\geq 40.0$, respectively) was associated with more than doubled risks of infant mortality (fig $3 \Downarrow$ ). Risk of neonatal mortality consistently increased with maternal BMI, and obesity grade 2 and 3 were also associated with increased risks of postneonatal mortality. Risk estimates were essentially unchanged after multiple imputations of missing values on BMI and other covariates (fig $3 \Downarrow$ ).

Risks of infant mortality associated with maternal BMI did not change over time. Adjusted odds ratios (95\% confidence intervals) for infant mortality per BMI unit increase during 1992-96, 1997-2000, 2001-05, and 2006-10 were 1.03 (1.01 to 1.04$), 1.04$ (1.03 to 1.06$), 1.04$ (1.02 to 1.05$)$, and 1.04 (1.03 to 1.06), respectively. Adjusting for parity may not adequately control for adverse birth events in previous pregnancies, and we therefore estimated infant mortality risks stratified by parity. Adjusted odds ratios of infant mortality were similar among births to all women (as presented in fig $3 \Downarrow$ ), for primiparous women, and for multiparous women (table A of data supplement).

To investigate whether BMI related risks of infant mortality may be influenced by obesity related maternal disorders, we performed sensitivity analyses restricted to mothers without hypertensive or diabetic disorders (morbidities related to obesity). However, the risk estimates were virtually unchanged compared to those presented in figure $3 \Downarrow$ (table B of data supplement). In analyses stratified by mother's country of birth, associations were of the same magnitude among Swedish born women and women born outside Sweden (table D, data supplement).

We recently reported that maternal obesity was associated with an increased risk of preterm delivery within this cohort, ${ }^{7}$ and preterm infants are at increased risk of infant mortality. We therefore stratified analyses by gestational length, into very preterm (22-31 weeks), moderately preterm (32-36 weeks), and term births ( $\geq 37$ weeks). The association between maternal BMI and infant mortality was primarily confined to term births, where the risks related to overweight and obesity were mainly increased in the neonatal period (table $2 \Downarrow$ ). Only obesity grade $2-3$ (BMI $\geq 35.0$ ) was associated with infant mortality in very preterm and moderately preterm births.

Next, we explored associations between maternal BMI and causes of infant mortality in term infants. Eighty one per cent of infant deaths in term infants were attributed to congenital anomalies, birth asphyxia, other neonatal morbidities, sudden infant death syndrome (SIDS), or infections (table E, data supplement). Risks of infant deaths due to birth asphyxia and other neonatal morbidities increased with maternal overweight and obesity (table $3 \Downarrow$ ). Compared with infants of mothers with normal weight (BMI 18.5-24.9), infants of mothers with obesity grade $2-3$ (BMI $\geq 35.0)$ had increased mortality risks due to congenital anomalies and SIDS.

Finally we estimated the fraction of infant deaths that could be attributed to maternal overweight or obesity (BMI $\geq 25.0)$ and to maternal smoking, provided that relationships were causal. The population attributable fraction (PAF) related to maternal overweight and obesity was $11 \%$ within the cohort,

corresponding to 458 infant deaths. Among term births, the PAF of infant mortality was also $11 \%$, corresponding to 256 infants deaths, indicating that $202(45 \%)$ of excess deaths associated with maternal BMI $\geq 25.0$ occur in preterm born infants. The PAF of infant mortality related to smoking was estimated to be $6.9 \%$, corresponding to 333 deaths within the cohort.

\section{Discussion}

\section{Principal findings}

In a nationwide cohort, we found that risks of infant mortality increased with maternal body mass index (BMI) among overweight and obese women. The association between maternal 
overweight and infant mortality was modest. This is in contrast with most, but not all, other studies, which found associations only between maternal obesity (not overweight) and infant mortality. ${ }^{8-11}$ Our data support that the association between maternal BMI and mortality risk is most evident in the neonatal period, ${ }^{9}{ }^{10}$ but we also found that the risk of postneonatal mortality was doubled among women with obesity grade 2 and 3 (BMI $\geq 35.0$ ). The increased infant mortality risk was primarily explained by an increased mortality risk in term infants (deaths due to birth asphyxia, other neonatal morbidities, and congenital anomalies) and an increased prevalence of preterm deliveries.

In this cohort, $24 \%$ of women were overweight and $9 \%$ were obese in early pregnancy. Provided that associations were causal, we estimated that $11 \%$ of infant deaths were attributed to maternal overweight and obesity. In Sweden, the reduction of the overall infant mortality rate $(0.3 \%)$ would be small if all pregnant women became normal weight as infant mortality is lower than in many other countries. ${ }^{22}$ In addition to a relatively low rate of preterm births, ${ }^{22}$ we speculate that uniform and free antenatal and paediatric health services contribute to good infant health. Yet, the number of infant deaths attributed maternal BMI $\geq 25.0$ was similar to the total number of infant deaths due to sudden infant death syndrome (SIDS) during the same time period.

\section{Comparison with other studies}

Associations between maternal overweight and obesity and infant mortality could be plausible, as pregnancy complications known to affect infant health are more common among overweight and obese mothers. Overweight and obese mothers are more often electively delivered preterm due to increased risks of obesity related pregnancy complications and are also at increased risk of spontaneous extremely preterm delivery ( $<28$ weeks). ${ }^{12}$ Preterm infants are often affected by serious neonatal morbidities. ${ }^{23}$ In addition, diabetic disorders are more common among overweight and obese mothers. ${ }^{12}$ An abnormal blood glucose homeostasis during pregnancy may not only be teratogenic and lead to congenital anomalies but may also accelerate fetal growth resulting in macrosomia that predisposes to traumatic delivery and birth asphyxia in term deliveries. ${ }^{25-27}$ However, when we restricted the analyses to women without obesity related disorders, the BMI related risks of infant mortality were essentially unchanged, indicating that maternal overweight and obesity are independently associated with infant mortality.

Cause-specific mortality related to maternal overweight and obesity has not previously been systematically examined. In a cohort study including 24505 infants, of whom 75 died during infancy, an increased neonatal mortality risk was found in infants of obese mothers, but no specific causes of death could be identified. ${ }^{28}$ A case-control study including 4265 infant deaths concluded that the excess infant mortality among obese women was mostly related to pregnancy complications leading to preterm birth and low birth weight. ${ }^{29}$ However, this study was based on births in 1988, before the introduction of antenatal steroids and surfactant, which today are lifesaving therapies for preterm infants. ${ }^{24} 30$

We found that risk of infant death due to birth asphyxia increased with maternal BMI among infants of overweight and obese mothers. High maternal BMI increases the risk of fetal macrosomia, ${ }^{27}$ and being born large-for-gestational-age is a risk factor for infant death due to birth asphyxia in term infants. ${ }^{26}$ We recently reported that maternal overweight or obesity increases the risks of severe asphyxia related outcomes in term infants, including meconium aspiration, neonatal seizures, and low (0-3) Apgar scores at 5 and 10 minutes. ${ }^{31}$ Maternal obesity is also linked to increased risks of persistent pulmonary hypertension in the newborn and septicaemia with group B streptococci, two serious conditions associated with neonatal mortality. ${ }^{32} 33$

Obesity grade $2-3$ (BMI $\geq 35.0)$ was associated with infant mortality due to congenital anomalies and sudden infant death syndrome (SIDS) in term deliveries. Maternal obesity is an established risk factor for potentially life threatening congenital anomalies. ${ }^{34}$ Our finding that the risk of SIDS was increased in women with obesity grade 2-3 (BMI $\geq 35.0$ ) was more unexpected. An increased risk of SIDS has previously been reported in infants of obese mothers with a high gestational weight gain. ${ }^{29}$ The association of maternal obesity and SIDS could also be explained by residual confounding. Obese women are more likely to smoke and to have difficulties in breastfeeding, which are risk factors for SIDS. ${ }^{35-37}$ However, given that there were only 20 SIDS deaths of mothers with obesity grade 2-3, the association between maternal BMI and SIDS could be due to chance.

\section{Strengths and limitations of study}

Our findings are strengthened by the population based approach, including almost 1.6 million live singleton born infants with information on maternal BMI. This enabled us not only to investigate how maternal BMI was associated with infant mortality risk in preterm and term births, but also to study cause-specific infant mortality in term births. The prospective data collection minimised systematic biases related to the outcome. The use of maternal BMI is an advantage because it is a valid proxy for adiposity; the correlation between maternal BMI and total body fat is high, especially in early pregnancy. ${ }^{38} 39$ Finally, risk estimates were adjusted for maternal smoking and education, indicators of socioeconomic status. ${ }^{40}$

Maternal BMI was calculated from self reported height and weight measured at the first antenatal visit. Self reported height, prone to overestimation, and pregnancy related weight gain before weight measurement at the first antenatal visit may lead to either underestimation or overestimation of a woman's pre-pregnancy BMI. ${ }^{14}{ }^{41}$ However, we find it unlikely that such errors would lead to systematic misclassification with regard to infant mortality. Information on BMI was missing in one of eight mothers, and infants of these mothers had a high mortality rate. We used multiple imputation techniques to assess selection bias due to missing data. The risk estimates after multiple imputations were similar to those in analyses based on women with known BMI, indicating that selection bias was not a major limitation.

We were not able to explore effects of weight gain during pregnancy as such information was lacking for the vast majority of women. However, current measurements of weight gain during pregnancy correlate with gestational length and could therefore introduce serious bias in studies of outcomes that also correlate with gestational length. ${ }^{42}$ Furthermore, actual weight gain trajectories in women with good perinatal outcomes deviate over gestation from recommendations by the Institute of Medicine, leading to an increasing difference between recommended and observed weight gain in term births. ${ }^{42}$

When we restricted analyses to women without obesity related complications, the association between maternal BMI and infant mortality was virtually unchanged. Although this finding suggests an independent association with maternal BMI, it is 
possible that some cases of hypertensive or diabetic disorders were undiagnosed and thus, not accounted for.

The BMI related risks of infant mortality were very similar in Swedish born women and in the heterogeneous group of non-Swedish born women, both predominantly white populations.

Despite that we could adjust the BMI related risks for several maternal characteristics (age, parity, smoking, education level, height, country of birth, and year of delivery), we cannot exclude the possibility of residual social confounding. For example, we had no information on father's socioeconomic characteristics.

A within-siblings study would decrease potential residual confounding by characteristics that remain fixed between pregnancies. However, there are several difficulties to perform such analyses. The range of exposure (that is, differences in maternal BMI) within siblings discordant for infant mortality will be limited. ${ }^{2}$ The rates of infant mortality also decrease over calendar time. Furthermore, an infant death will result in increased supervision to avoid recurrence of the event-that is, outcomes after subsequent births are not independent of previous births. Finally, in a sibling-controlled study it would be difficult to adjust for the time-varying confounding by parity, as women tend to slightly gain weight over time.

\section{Conclusions and policy implications}

Worldwide, overweight and obesity have rapidly become prevalent among young pregnant women..$^{43}$ Our study needs to be replicated in other populations, and the pathways behind the association between maternal overweight and obesity and risk of infant mortality should be explored. But we also argue that there is enough evidence for public health officials to act against the obesity epidemic to promote infant health.

Contributors: SJ, EV, FG, and SC conceived and designed the study. SC acquired data. SJ, EV, MA, AEB, FG, and SC analysed and interpreted the data, and wrote and critically revised the manuscript. SJ, FG, and SC performed the statistical analysis and provided administrative, technical, and material support. SC obtained funding and supervised the study.

Funding: An unrestricted grant from Karolinska Institutet (Distinguished Professor Award to SC) and from the Swedish Research Council for Health, Working Life and Welfare (project No 2014-0073).

Competing interests: All authors have completed the ICMJE uniform disclosure form at www.icmje.org/coi_disclosure.pdf and declare: no support from any organisation for the submitted work; no financial relationships with any organisations that might have an interest in the submitted work in the previous three years; no other relationships or activities that could appear to have influenced the submitted work." Ethical approval: The study was approved by the Research Ethics Committee at Karolinska Institutet, Stockholm, Sweden (No 2012/4:9). Data access: All authors had full access to all of the data in the study and take responsibility for the integrity of the data and the accuracy of the data analyses.

Transparency: The manuscript is an honest, accurate, and transparent account of the study being reported. No important aspects of the study have been omitted. There are no discrepancies from the study as planned.

Data sharing: No additional data available.

Guelinckx I, Devlieger R, Beckers K, Vansant G. Maternal obesity: pregnancy complications, gestational weight gain and nutrition. Obes Rev 2008:9:140-50.

2 Villamor $E$, Cnattingius $S$. Interpregnancy weight change and risk of adverse pregnancy outcomes: a population-based study. Lancet 2006;368:1164-70.

3 Sibai B, Dekker G, Kupferminc M. Pre-eclampsia. Lancet 2005;365:785-99.
4 Correa A, Gilboa SM, Besser LM, Botto LD, Moore CA, Hobbs CA, et al. Diabetes mellitus and birth defects. Am J Obstet Gynecol 2008:199:237.e1-9.

5 Wendland EM, Torloni MR, Falavigna M, Trujillo J, Dode MA, Campos MA, et al. Gestational diabetes and pregnancy outcomes-a systematic review of the World Health Organization (WHO) and the International Association of Diabetes in Pregnancy Study Groups (IADPSG) diagnostic criteria. BMC Pregnancy Childbirth 2012;12:23.

6 Zhang X, Decker A, Platt RW, Kramer MS. How big is too big? The perinatal consequences of fetal macrosomia. Am J Obstet Gynecol 2008;198:517.e1-6.

7 Cnattingius S, Villamor E, Johansson S, Edstedt Bonamy AK, Persson M, Wikstrom AK, et al. Maternal obesity and risk of preterm delivery. JAMA 2013;309:2362-70.

8 Meehan S, Beck CR, Mair-Jenkins J, Leonardi-Bee J, Puleston R. Maternal obesity and infant mortality: a meta-analysis. Pediatrics 2014;133:863-71.

9 Aune D, Saugstad OD, Henriksen T, Tonstad S. Maternal body mass index and the risk of fetal death, stillbirth, and infant death: a systematic review and meta-analysis. JAMA 2014;311:1536-46.

10 Salihu HM, Alio AP, Wilson RE, Sharma PP, Kirby RS, Alexander GR. Obesity and extreme obesity: new insights into the black-white disparity in neonatal mortality. Obstet Gynecol 2008;111:1410-6.

11 Thompson DR, Clark CL, Wood B, Zeni MB. Maternal obesity and risk of infant death based on Florida birth records for 2004. Public Health Rep 2008;123:487-93.

12 Stothard KJ, Tennant PW, Bell R, Rankin J. Maternal overweight and obesity and the risk of congenital anomalies: a systematic review and meta-analysis. JAMA 2009;301:636-50.

13 Ludvigsson JF, Otterblad-Olausson P, Pettersson BU, Ekbom A. The Swedish personal identity number: possibilities and pitfalls in healthcare and medical research. EurJ Epidemiol 2009;24:659-67.

14 National Board of Health and Welfare (Socialstyrelsen). Swedish Medical Birth Register A summary of content and quality. 2003-112-3. www.socialstyrelsen.se/publikationer2003/ 2003-112-3.

15 National Board of Health and Welfare (Socialstyrelsen). Causes of death 2012, publication nb 2013-8-6. www.socialstyrelsen.se/publikationer2013/2013-8-6/.

16 Statistics Sweden. Tables on the population in Sweden 2009. 2010. www.scb.se/Pages/ PublishingCalendarViewInfo_ 259924.aspx?PublObjld $=11400$.

17 Statistics Sweden. Evaluation of the Swedish register of education. 2006. www.scb.se/ Pages/PublishingCalendarViewInfo__259924.aspx?PublObjld=3299.

18 World Health Organization. Global database on body mass index: BMI classification. http //apps.who.int/bmi/index.jsp?introPage=intro_3.html.

19 Hogberg U, Larsson N. Early dating by ultrasound and perinatal outcome. A cohort study. Acta Obstet Gynecol Scand 1997;76:907-12.

20 George L, Granath F, Johansson AL, Cnattingius S. Self-reported nicotine exposure and plasma levels of cotinine in early and late pregnancy. Acta Obstet Gynecol Sca 2006;85:1331-7.

21 Rockhill B, Newman B, Weinberg C. Use and misuse of population attributable fractions. Am J Pub Health 1998;88:15-9.

22 MacDorman MF, Mathews TJ. Behind international rankings of infant mortality: how the United States compares with Europe. Int J Health Serv 2010;40:577-88.

23 Ambalavanan N, Carlo WA, Tyson JE, Langer JC, Walsh MC, Parikh NA, et al. Outcome trajectories in extremely preterm infants. Pediatrics 2012;130:e115-25.

24 Bahadue FL, Soll R. Early versus delayed selective surfactant treatment for neonatal respiratory distress syndrome. Cochrane Database Syst Rev 2012;11:CD001456.

25 Eriksson UJ, Wentzel P. Diabetic embryopathy. Methods Molec Biol 2012;889:425-36.

26 Altman M, Edstedt Bonamy AK, Wikstrom AK, Cnattingius S. Cause-specific infant mortality in a population-based Swedish study of term and post-term births: the contribution of gestational age and birth weight. BMJ Open 2012;2:e001152.

27 Robinson H, Tkatch S, Mayes DC, Bott N, Okun N. Is maternal obesity a predictor of shoulder dystocia? Obstet Gynecol 2003;101:24-7.

28 Kristensen J, Vestergaard M, Wisborg K, Kesmodel U, Secher NJ. Pre-pregnancy weight and the risk of stillbirth and neonatal death. BJOG 2005;112:403-8.

29 Chen A, Feresu SA, Fernandez C, Rogan WJ. Maternal obesity and the risk of infant death in the United States. Epidemiology 2009;20:74-81.

30 Roberts D, Dalziel S. Antenatal corticosteroids for accelerating fetal lung maturation for women at risk of preterm birth. Cochrane Database Syst Rev 2006;(3):CD004454.

31 Persson M, Johansson S, Villamor E, Cnattingius S. Maternal overweight and obesity and risks of severe birth-asphyxia-related complications in term infants: a population-based cohort study in Sweden. PLoS Med 2014;11:e1001648.

32 Hernandez-Diaz S, Van Marter LJ, Werler MM, Louik C, Mitchell AA. Risk factors for persistent pulmonary hypertension of the newborn. Pediatrics 2007;120:e272-82.

33 Hakansson S, Kallen K. High maternal body mass index increases the risk of neonatal early onset group B streptococcal disease. Acta Paediatrica 2008;97:1386-9.

34 Jolly MC, Sebire NJ, Harris JP, Regan L, Robinson S. Risk factors for macrosomia and its clinical consequences: a study of 350,311 pregnancies. Eur J Obstet, Gynecol Reprod Biol 2003;111:9-14

35 Carpenter R, McGarvey C, Mitchell EA, Tappin DM, Vennemann MM, Smuk M, et al. Bed sharing when parents do not smoke: is there a risk of SIDS? An individual level analysis of five major case-control studies. BMJ Open 2013;3:e002299.

36 Cawley J, Markowitz S, Tauras J. Lighting up and slimming down: the effects of body weight and cigarette prices on adolescent smoking initiation. $J$ Health Econom 2004:23:293-311.

37 Chapman DJ, Morel K, Bermudez-Millan A, Young S, Damio G, Perez-Escamilla R. Breastfeeding education and support trial for overweight and obese women: a randomized trial. Pediatrics 2013;131:e162-70.

38 Lindsay CA, Huston L, Amini SB, Catalano PM. Longitudinal changes in the relationship between body mass index and percent body fat in pregnancy. Obstet Gyneco 1997;89:377-82.

39 Sewell MF, Huston-Presley L, Amini SB, Catalano PM. Body mass index: a true indicator of body fat in obese gravidas. J Reprod Med 2007;52:907-11.

40 Villalbi JR, Salvador J, Cano-Serral G, Rodriguez-Sanz MC, Borrell C. Maternal smoking, social class and outcomes of pregnancy. Paediatr Perinatal Epidemiol 2007:21:441-7.

41 Brunner Huber LR. Validity of self-reported height and weight in women of reproductive age. Matern Child Health J 2007;11:137-44.

42 Hutcheon JA, Bodnar LM, Joseph KS, Abrams B, Simhan HN, Platt RW. The bias in current measures of gestational weight gain. Paediatr Perinatal Epidemiol 2012;26:109-16.

43 Black RE, Victora CG, Walker SP, Bhutta ZA, Christian P, de Onis M, et al. Maternal and child undernutrition and overweight in low-income and middle-income countries. Lancet 2013;382:427-51. 


\section{What is already known on this topic}

Women of childbearing age have a high prevalence of overweight and obesity

Meta-analyses show that maternal obesity (body mass index $(\mathrm{BMI}) \geq 30$ ) is associated with increased risk of infant mortality

\section{What this study adds}

Not only maternal obesity but also maternal overweight (BMI 25-29) is associated with increased infant mortality risk, and the risk increases with increasing BMI

The excess mortality seems to be explained by an increased mortality risk in term births, mostly due to birth asphyxia and other neonatal morbidities, and by an increased prevalence of preterm births

\section{Accepted: 15 October 2014}

Cite this as: BMJ 2014;349:g6572
This is an Open Access article distributed in accordance with the Creative Commons Attribution Non Commercial (CC BY-NC 4.0) license, which permits others to distribute, remix, adapt, build upon this work non-commercially, and license their derivative works on different terms, provided the original work is properly cited and the use is non-commercial. See: http://creativecommons.org/licenses/by-nc/4.0/. 


\section{Tables}

Table 1/ Maternal characteristics and rates of infant, neonatal, and postneonatal mortality (deaths during first year, deaths within 28 days of life, and deaths after 28 days to 1 year, respectively). Live singleton births in Sweden 1992-2010 ( $n=1857822)$

\begin{tabular}{|c|c|c|c|c|}
\hline & \multirow[b]{2}{*}{ No $(\%)$ of deliveries } & \multicolumn{3}{|c|}{ No of infant deaths (rate/1000) } \\
\hline & & Total & Neonatal & Postneonatal \\
\hline Total & $1857822(100.0)$ & $5428(2.9)$ & $3466(1.9)$ & $1962(1.0)$ \\
\hline \multicolumn{5}{|c|}{ Body mass index ${ }^{*}$ : } \\
\hline$\leq 18.4$ & $41486(2.2)$ & $109(2.6)$ & $59(1.4)$ & $50(1.2)$ \\
\hline $18.5-24.9$ & $1014513(54.6)$ & $2393(2.4)$ & $1495(1.5)$ & $898(0.9)$ \\
\hline $25.0-29.9$ & 385599 (20.8) & $1150(3.0)$ & $724(1.9)$ & $426(1.1)$ \\
\hline $30.0-34.9$ & 114421 (6.2) & $384(3.4)$ & $259(2.3)$ & $125(1.1)$ \\
\hline $35.0-39.9$ & $32677(1.8)$ & $166(5.1)$ & $111(3.4)$ & $55(1.7)$ \\
\hline$\geq 40.0$ & $10855(0.6)$ & $63(5.8)$ & $38(3.5)$ & $25(2.3)$ \\
\hline Missing & $258271(13.9)$ & $1163(4.5)$ & $780(3.0)$ & $383(1.5)$ \\
\hline \multicolumn{5}{|l|}{ Age (years): } \\
\hline$\leq 19$ & $36035(1.9)$ & $173(4.8)$ & $99(2.7)$ & $74(2.0)$ \\
\hline $20-24$ & $280341(15.1)$ & $980(3.5)$ & $577(2.0)$ & $403(1.4)$ \\
\hline $25-29$ & 616455 (33.2) & $1621(2.6)$ & $1012(1.6)$ & $609(1.0)$ \\
\hline $30-34$ & $603441(32.0)$ & $1603(2.6)$ & $1053(1.7)$ & $550(0.9)$ \\
\hline$\geq 35$ & 321550 (17.3) & $1051(3.3)$ & $725(2.2)$ & $326(1.0)$ \\
\hline \multicolumn{5}{|l|}{ Parity $(n)$ : } \\
\hline 1 & 802870 (43.2) & $2274(2.8)$ & $1586(2.0)$ & $688(0.8)$ \\
\hline 2 & $677237(36.4)$ & $1794(2.6)$ & $1066(1.6)$ & $728(1.1)$ \\
\hline 3 & $262047(14.1)$ & $808(3.1)$ & $498(1.9)$ & $310(1.2)$ \\
\hline$\geq 4$ & $115668(6.2)$ & $552(4.8)$ & $316(2.7)$ & $236(2.0)$ \\
\hline \multicolumn{5}{|l|}{ Smoking: } \\
\hline No & $1544424(83.1)$ & $3821(2.5)$ & $2506(1.6)$ & $1315(0.8)$ \\
\hline Yes & 215371 (11.6) & $985(4.6)$ & $502(2.3)$ & $483(2.2)$ \\
\hline Missing & 98027 (5.3) & $622(6.3)$ & $458(4.7)$ & $164(1.7)$ \\
\hline \multicolumn{5}{|l|}{ Height $(\mathrm{cm})$ : } \\
\hline$\leq 154$ & 54637 (2.9) & 197 (3.6) & $123(2.2)$ & $74(1.4)$ \\
\hline 155-164 & $607971(32.0)$ & $1805(3.0)$ & $1123(1.8)$ & $682(1.1)$ \\
\hline 165-174 & 891337 (48.0) & $2247(2.5)$ & $1426(1.6)$ & $821(0.9)$ \\
\hline$\geq 175$ & $163870(8.8)$ & $378(2.3)$ & $238(1.4)$ & $140(0.9)$ \\
\hline Missing & $140007(7.5)$ & $801(5.7)$ & $556(4.0)$ & $245(1.8)$ \\
\hline \multicolumn{5}{|c|}{ Education (years): } \\
\hline$\leq 9$ & $186101(10.0)$ & $820(4.4)$ & $443(2.4)$ & $377(2.0)$ \\
\hline $10-11$ & 381899 (20.6) & $1398(3.7)$ & $892(2.3)$ & $506(1.3)$ \\
\hline 12 & 446251 (24.0) & $1189(2.7)$ & $784(1.8)$ & $405(0.9)$ \\
\hline $13-14$ & 272694 (14.7) & $689(2.5)$ & $453(1.7)$ & $236(0.9)$ \\
\hline$\geq 15$ & $537292(28.9)$ & $1223(2.3)$ & $833(1.6)$ & $390(0.7)$ \\
\hline Missing & 33585 (1.8) & 109 (3.2) & $61(1.8)$ & $48(1.4)$ \\
\hline \multicolumn{5}{|l|}{ Country of birth: } \\
\hline Sweden & $1503244(80.9)$ & $4217(2.8)$ & $2701(1.8)$ & $1516(1.0)$ \\
\hline Other Nordic & $43201(2.3)$ & $164(3.8)$ & $95(2.2)$ & $69(1.6)$ \\
\hline Outside Nordic & $291432(15.7)$ & $1007(3.5)$ & $643(2.2)$ & $364(1.2)$ \\
\hline Missing & $19945(1.1)$ & $40(2.0)$ & $27(1.4)$ & $13(0.6)$ \\
\hline \multicolumn{5}{|l|}{ Year of delivery: } \\
\hline 1992-1996 & $529004(28.5)$ & 2045 (3.9) & $1284(2.4)$ & $761(1.4)$ \\
\hline
\end{tabular}


Table 1 (continued)

\begin{tabular}{lcccc} 
& & \multicolumn{3}{c}{ No of infant deaths (rate/1000) } \\
\cline { 3 - 5 } & No (\%) of deliveries & Total & Neonatal & Postneonatal \\
\hline $1997-2000$ & $337172(18.1)$ & $1008(3.0)$ & $645(1.9)$ & $363(1.1)$ \\
\hline $2001-2005$ & $468698(25.2)$ & $1219(2.6)$ & $800(1.7)$ & $419(0.9)$ \\
\hline $2006-2010$ & $522948(28.1)$ & $1156(2.2)$ & $737(1.4)$ & $419(0.8)$ \\
\hline & & & & \\
$*$ Weight $(\mathrm{kg}) /(\text { height }(\mathrm{m}))^{2}$ & & & \\
†Includes Denmark, Finland, Iceland and Norway. &
\end{tabular}

tIncludes Denmark, Finland, Iceland and Norway. 
Table 2| Maternal body mass index (BMI) in early pregnancy and risks of infant, neonatal, and postneonatal mortality (deaths during the first year, and deaths within and after 28 days of life, respectively) in live singleton births in Sweden 1992-2010 ( $n=1857822$ ). Analyses are stratified by gestational age

\begin{tabular}{|c|c|c|c|c|c|c|}
\hline \multirow[b]{2}{*}{ BMI } & \multicolumn{2}{|c|}{ Infant mortality } & \multicolumn{2}{|c|}{ Neonatal mortality $†$} & \multicolumn{2}{|c|}{ Postneonatal mortality } \\
\hline & $\begin{array}{l}\text { No of deaths } \\
\text { (rate/1000) }\end{array}$ & $\begin{array}{c}\text { Adjusted odds ratio } \\
(95 \% \mathrm{Cl})^{\star}\end{array}$ & $\begin{array}{l}\text { No of deaths } \\
\text { (rate/1000) }\end{array}$ & $\begin{array}{l}\text { Adjusted odds ratio } \\
(95 \% \mathrm{Cl})^{*}\end{array}$ & $\begin{array}{l}\text { No of deaths } \\
\text { (rate/1000) }\end{array}$ & $\begin{array}{l}\text { Adjusted odds ratio } \\
(95 \% \mathrm{Cl})^{*}\end{array}$ \\
\hline \multicolumn{7}{|c|}{ Very preterm delivery $(22-31$ weeks) $(n=12$ 888)§ } \\
\hline & $(n=1584)$ & & $(n=1318)$ & & $(n=266)$ & \\
\hline Per unit increase & & 1.01 (1.00 to 1.03$)$ & & $1.02(1.00$ to 1.03$)$ & & $1.00(0.96$ to 1.03$)$ \\
\hline$\leq 18.4$ & $32(106)$ & 0.90 (0.61 to 1.33$)$ & $26(86)$ & $0.91(0.60$ to 1.40$)$ & $6(21)$ & $0.86(0.37$ to 2.02$)$ \\
\hline $18.5-24.9$ & $651(114)$ & 1.00 (ref) & $532(93)$ & 1.00 (ref) & $119(23)$ & 1.00 (ref) \\
\hline $25.0-29.9$ & $291(116)$ & $1.06(0.91$ to 1.24$)$ & $255(101)$ & $1.15(0.98$ to 1.36$)$ & $36(16)$ & $0.70(0.47$ to 1.02$)$ \\
\hline $30.0-34.9$ & $104(109)$ & $1.00(0.80$ to 1.26$)$ & $86(90)$ & $1.03(0.80$ to 1.32$)$ & $18(21)$ & $0.91(0.54$ to 1.53$)$ \\
\hline$\geq 35.0$ & $71(141)$ & 1.36 (1.04 to 1.79$)$ & $57(113)$ & 1.35 (1.00 to 1.82$)$ & $14(31)$ & $1.38(0.76$ to 2.50$)$ \\
\hline Missing & $435(149)$ & - & $362(124)$ & - & $73(28)$ & - \\
\hline \multicolumn{7}{|c|}{ Moderately preterm delivery $(32-36$ weeks) $(n=80531) \S$} \\
\hline & $(n=1013)$ & & $(n=740)$ & & $(n=273)$ & \\
\hline Per unit increase & & 1.03 (1.01 to 1.04$)$ & & 1.03 (1.02 to 1.05$)$ & & 1.01 (0.98 to 1.04$)$ \\
\hline$\leq 18.4$ & $16(6.7)$ & 0.55 (0.33 to 0.93$)$ & $11(4.6)$ & $0.54(0.29$ to 1.01$)$ & $5(2.1)$ & $0.57(0.23$ to 1.42$)$ \\
\hline $18.5-24.9$ & $456(11)$ & 1.00 (ref) & $326(8.0)$ & 1.00 (ref) & $130(3.2)$ & 1.00 (ref) \\
\hline $25.0-29.9$ & $226(14)$ & 1.23 (1.04 to 1.45$)$ & $167(10)$ & 1.25 (1.03 to 1.52$)$ & $59(3.7)$ & $1.18(0.85$ to 1.63$)$ \\
\hline $30.0-34.9$ & $73(14)$ & $1.16(0.89$ to 1.50$)$ & $55(10)$ & $1.22(0.91$ to 1.65$)$ & $18(3.4)$ & 1.00 (0.59 to 1.68$)$ \\
\hline$\geq 35.0$ & $42(18)$ & 1.65 (1.19 to 2.29$)$ & $31(13)$ & 1.73 (1.19 to 2.54$)$ & $11(4.7)$ & $1.44(0.76$ to 2.71$)$ \\
\hline Missing & $200(15)$ & - & $150(11)$ & - & $50(3.8)$ & - \\
\hline \multicolumn{7}{|c|}{ Term delivery ( $\geq 37$ weeks) $(n=1764$ 403)§ } \\
\hline & $(n=2831)$ & & $(n=1408)$ & & $(n=1423)$ & \\
\hline Per unit increase & & 1.04 (1.03 to 1.05$)$ & & 1.05 (1.04 to 1.07$)$ & & $1.02(1.01$ to 1.04$)$ \\
\hline$\leq 18.4$ & $61(1.6)$ & $1.07(0.82$ to 1.39$)$ & $22(0.6)$ & $0.79(0.51$ to 1.24$)$ & $39(1.0)$ & $1.31(0.94$ to 1.81$)$ \\
\hline $18.5-24.9$ & $1286(1.3)$ & 1.00 (ref) & $637(0.7)$ & 1.00 (ref) & $649(0.7)$ & 1.00 (ref) \\
\hline $25.0-29.9$ & $633(1.7)$ & 1.28 (1.16 to 1.42$)$ & $302(0.8)$ & $1.27(1.11$ to 1.47$)$ & $331(0.9)$ & $1.29(1.12$ to 1.48$)$ \\
\hline $30.0-34.9$ & $207(1.9)$ & $1.37(1.18$ to 1.60$)$ & $118(1.1)$ & $1.71(1.39$ to 2.10$)$ & $89(0.8)$ & 1.09 (0.86 to 1.37$)$ \\
\hline$\geq 35.0$ & $116(2.9)$ & 2.07 (1.70 to 2.53$)$ & $61(1.5)$ & $2.40(1.82$ to 3.17$)$ & $55(1.4)$ & $1.80(1.35$ to 2.40$)$ \\
\hline Missing & $528(2.2)$ & - & $268(1.1)$ & - & $260(1.1)$ & - \\
\hline
\end{tabular}

*Adjusted for maternal characteristics (age, parity, smoking, height, education, country of origin, year of delivery)

†Analyses on neonatal mortality included infants who died during the postneonatal period

$\ddagger$ Analyses on postneonatal mortality included only infants surviving the neonatal period.

$\S$ The number of births included in each adjusted analysis were: very preterm delivery (infant and neonatal mortality $n=9495$, postneonatal mortality $n=8571$ ); moderately preterm delivery (infant and neonatal mortality $n=64451$, postneonatal mortality $n=63888$ ); term delivery (infant and neonatal mortality $n=1471689$, postneonatal mortality $n=1470595)$. 
Table 3| Maternal body mass index (BMI) in early pregnancy and risks of infant mortality in live singleton term births in Sweden 1992-2010 ( $n=1764$ 403): analyses stratified by causes of death

\begin{tabular}{|c|c|c|c|}
\hline \multirow[b]{2}{*}{ BMI } & \multirow[b]{2}{*}{ No of deaths (rate/1000) } & \multicolumn{2}{|c|}{ Odds ratio $(95 \% \mathrm{Cl})$} \\
\hline & & Crude & Adjusted $^{*}$ \\
\hline \multicolumn{4}{|c|}{ Congenital anomalies $(n=1108)$} \\
\hline$\leq 18.4$ & $21(0.54)$ & $1.00(0.65$ to 1.55$)$ & 1.01 (0.65 to 1.56$)$ \\
\hline $18.5-24.9$ & $529(0.55)$ & 1.00 (ref) & 1.00 (ref) \\
\hline $25.0-29.9$ & $229(0.62)$ & $1.14(0.97$ to 1.33$)$ & 1.16 (0.98 to 1.36$)$ \\
\hline $30.0-34.9$ & $72(0.67)$ & $1.20(0.94$ to 1.54$)$ & 1.13 (0.87 to 1.47$)$ \\
\hline$\geq 35.0$ & $45(1.11)$ & 2.02 (1.48 to 2.74$)$ & 2.15 (1.56 to 2.95$)$ \\
\hline Missing & $212(0.88)$ & - & - \\
\hline \multicolumn{4}{|c|}{ Birth asphyxia ( $n=245)$} \\
\hline$\leq 18.4$ & $3(0.08)$ & $0.80(0.25$ to 2.51$)$ & $0.87(0.27$ to 2.75$)$ \\
\hline $18.5-24.9$ & $94(0.10)$ & 1.00 (ref) & 1.00 (ref) \\
\hline $25.0-29.9$ & $70(0.19)$ & 1.96 (1.44 to 2.68$)$ & 2.19 (1.59 to 3.02$)$ \\
\hline $30.0-34.9$ & $25(0.23)$ & $2.38(1.53$ to 3.70$)$ & 2.79 (1.76 to 4.43$)$ \\
\hline$\geq 35.0$ & $11(0.27)$ & 2.79 (1.49 to 5.21$)$ & $3.21(1.65$ to 6.25$)$ \\
\hline Missing & $42(0.17)$ & - & - \\
\hline \multicolumn{4}{|c|}{ Other neonatal morbidity ( $n=267$ ) } \\
\hline$\leq 18.4$ & $7(0.18)$ & $1.63(0.76$ to 3.51$)$ & $1.78(0.83$ to 3.84$)$ \\
\hline $18.5-24.9$ & $107(0.11)$ & 1.00 (ref) & 1.00 (ref) \\
\hline $25.0-29.9$ & $65(0.18)$ & $1.60(1.18$ to 2.18$)$ & 1.57 (1.13 to 2.17$)$ \\
\hline $30.0-34.9$ & $27(0.25)$ & 2.26 (1.48 to 3.45$)$ & 2.47 (1.60 to 3.82$)$ \\
\hline$\geq 35.0$ & $15(0.37)$ & 3.34 (1.95 to 5.73$)$ & 3.44 (1.94 to 6.12$)$ \\
\hline Missing & $46(0.19)$ & - & - \\
\hline \multicolumn{4}{|c|}{ Sudden infant death syndrome (SIDS) $(n=460)$} \\
\hline$\leq 18.4$ & $12(0.31)$ & $1.42(0.79$ to 2.56$)$ & $1.08(0.60$ to 1.93$)$ \\
\hline $18.5-24.9$ & $209(0.22)$ & 1.00 (ref) & 1.00 (ref) \\
\hline $25.0-29.9$ & $111(0.30)$ & $1.40(1.11$ to 1.77$)$ & 1.31 (1.03 to 1.66$)$ \\
\hline $30.0-34.9$ & $29(0.27)$ & $1.22(0.82$ to 1.82$)$ & $1.06(0.71$ to 1.58$)$ \\
\hline$\geq 35.0$ & $20(0.49)$ & 2.25 (1.41 to 3.60$)$ & $1.88(1.17$ to 3.01$)$ \\
\hline Missing & $79(0.33)$ & - & - \\
\hline \multicolumn{4}{|c|}{ Infection ( $\mathrm{n}=207)$} \\
\hline$\leq 18.4$ & $7(0.18)$ & $2.08(0.96$ to 4.49$)$ & $1.74(0.80$ to 3.80$)$ \\
\hline $18.5-24.9$ & $84(0.09)$ & 1.00 (ref) & 1.00 (ref) \\
\hline $25.0-29.9$ & $52(0.14)$ & $1.63(1.16$ to 2.31$)$ & 1.56 (1.10 to 2.22$)$ \\
\hline $30.0-34.9$ & $11(0.10)$ & $1.17(0.63$ to 2.20$)$ & 1.01 (0.52 to 1.97$)$ \\
\hline$\geq 35.0$ & $4(0.10)$ & 1.13 (0.42 to 3.09$)$ & 1.08 (0.39 to 2.95$)$ \\
\hline Missing & $49(0.20)$ & - & \\
\hline
\end{tabular}

*Adjusted for maternal characteristics (age, parity, smoking, height, education, country of origin, year of delivery). The number of births included in each adjusted analysis is $n=1471689$. 


\section{Figures}

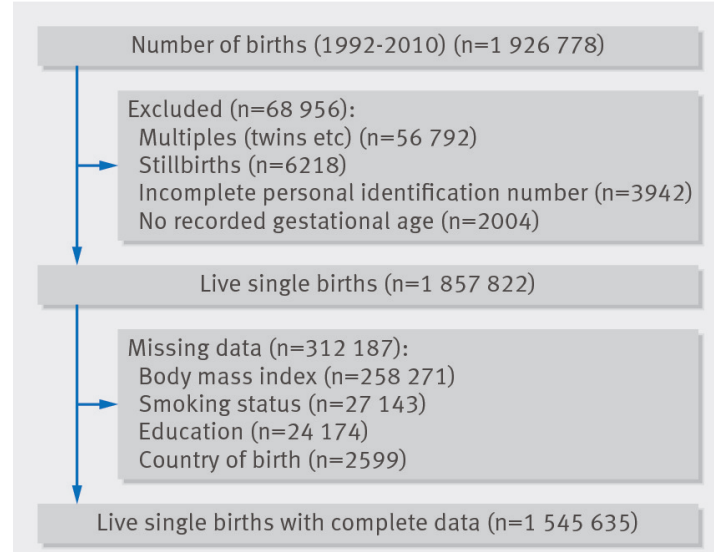

Fig 1 Births in Sweden 1992-2010. The study population includes 1857822 live single births in Sweden 1992-2010. Numbers of births with missing information on maternal body mass index (BMI), smoking status, education level, and country of birth are provided

$$
\mathrm{PAF}=1-\sum_{i=0}^{k} \frac{\mathrm{pd}(i)}{\operatorname{Adjusted} \mathrm{OR}(i)}
$$

$\mathrm{k}=$ number of exposure categories in addition to reference category $i=0$

$\mathrm{pd}(i)=$ proportion of cases falling into the $i$ th exposure category

Adjusted OR $(i)=$ adjusted odds ratio for the ith exposure category

Fig 2 Formula for calculating population attributable fraction $(\mathrm{PAF})^{21}$ 

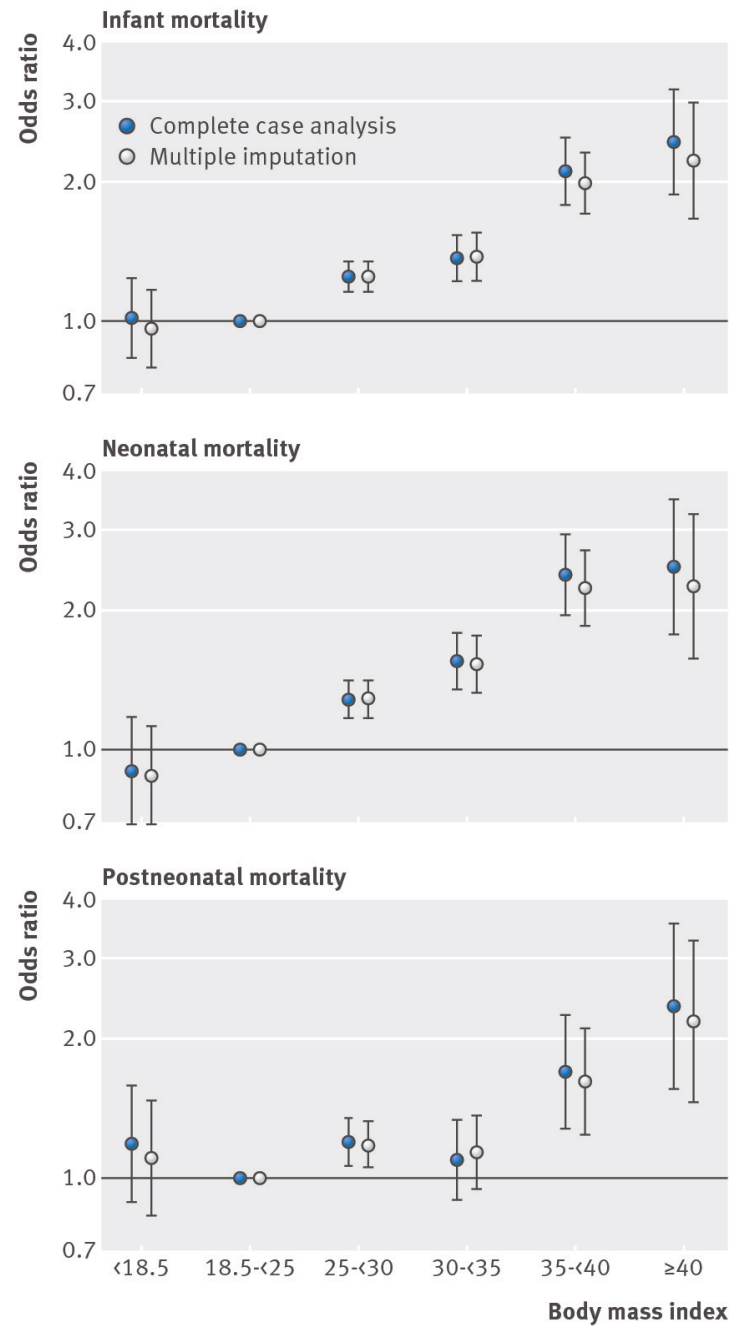

Fig 3 Maternal body mass index (BMI) in early pregnancy and risks of infant, neonatal, and postneonatal mortality (deaths during first year, deaths within 28 days of life, and deaths after 28 days to 1 year, respectively). Odds ratios were estimated both from the dataset with complete covariate information $(n=1545635$ for infant and neonatal mortality and $n=1543054$ for postneonatal mortality) and after multiple imputation of missing values ( $n=1857822$ for infant and neonatal mortality and $n=1854356$ for postneonatal mortality). Odds ratios were adjusted for maternal age, parity, smoking, education, height, country of birth, and year of delivery 